\title{
A growth spurt in pediatric sleep research
}

\author{
This article was published in the following Dove Press journal: \\ Nature and Science of Sleep \\ 29 April 2016 \\ Number of times this article has been viewed
}

\author{
Derek J Lam' \\ Steven A Shea ${ }^{2}$ \\ 'Department of Otolaryngology-Head \\ and Neck Surgery, ${ }^{2}$ Oregon Institute \\ of Occupational Health Sciences, \\ Oregon Health and Science University, \\ Portland, OR, USA
}

The awareness and understanding of the spectrum of pediatric sleep disorders has increased significantly in the last 20 years. While parents have always struggled with snoring children or behavioral difficulties around bedtime, only recently have parents and clinicians become aware of the potential long-term negative consequences of leaving these problems unaddressed. The diagnosis and management of pediatric sleep disorders can be uniquely challenging because of difficulties in assessing both the burden of disease and its downstream effects in the very young who are unable to clearly articulate their sleep-related experiences or relevant outcomes. Investigations in this age-group frequently require proxy parental assessments of sleep habits and outcomes or other innovative alternative methods of subjective assessment combined with objective measures that must be customized to the pediatric population. The impact of untreated sleep disorders during critical periods of early development on later cognition, behavior, and quality of life is potentially significant and far-reaching. This lends urgency to the need for more thorough and systematic investigation across the spectrum of pediatric sleep disorders.

Nature and Science of Sleep (NSS) is a relatively new international, peer-reviewed, open-access journal covering all aspects of sleep science and sleep medicine, including the neurophysiology and functions of sleep, the genetics of sleep, sleep and society, biological rhythms, dreaming, sleep disorders and therapy, and strategies to optimize healthy sleep. Interestingly, despite the broad topics covered by NSS, in the first 100 articles published in NSS, over 10\% were specific to sleep disorders in the pediatric age-group. These articles include three review articles that discuss the specific pediatric sleep diagnoses described in the International Classification of Sleep Disorders, ${ }^{1}$ the neurocognitive and behavior outcomes after treatment for sleep disordered breathing (SDB), ${ }^{2}$ and the relationship between pediatric sleep disorders and attention deficithyperactivity disorder (ADHD). ${ }^{3}$

In his review of pediatric sleep physiology and sleep disorders, El Shakankiry ${ }^{1}$ provides a concise summary of the unique features of pediatric sleep architecture and physiology that vary with age and are distinct from adult norms. Also discussed are the most common methods of assessing pediatric sleep, including key features of the sleep history and physical examination and objective investigations including polysomnography and actigraphy. A thorough review of the spectrum of pediatric sleep disorders is then presented according to the classification system described in the International
Oregon Institute of Occupational Health Sciences, Oregon Health and Science University, 3 I8I SW Sam Jackson Park Rd, Portland, OR, 97239, USA

Email sheast@ohsu.edu
Nature and Science of Sleep 2016:8 133-135 (c) (i) (5) 2016 Lam and Shea. This work is published and licensed by Dove Medical Press Limited. The full terms of this license are available at https://www.dovepress.com/terms. cc) ${ }_{\mathrm{BY}} \mathrm{NC}$ php and incorporate the Creative Commons Attribution - Non Commercial (unported, v3.0) License (http://creativecommons.org/licenses/by-nd/3.0/). By accessing the work you hereby accept the Terms. Non-commercial uses of the work are permitted without any further permission from Dove Medical Press Limited, provided the work is properly attributed. For

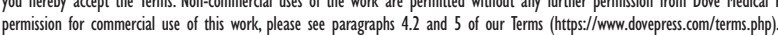


Classification of Sleep Disorders, Revised 2001. These include dyssomnias (problems with falling or staying asleep or excessive daytime sleepiness, which includes obstructive sleep apnea and inadequate sleep hygiene), parasomnias (behaviors or physiologic processes that interrupt sleep after sleep onset such as somnambulism or nightmares), and sleep disorders associated with medical conditions such as epilepsy or sudden infant death syndrome.

Unlike this broad overview of pediatric sleep disorders, a review by Kohler et $\mathrm{al}^{2}$ focuses on studies investigating the relationship between SDB and neurocognitive and behavioral outcomes, an area that has seen explosive growth in the number of articles published in recent years. Among the many studies that have examined this relationship, the article by Kohler et al utilized relatively strict criteria for review, requiring the use polysomnography to diagnose SDB and validated measures of neurocognitive performance and behavior. On the basis of the studies meeting these criteria, the authors were able to conclude that children with SDB have consistent neurocognitive impairments in executive function, attention, and general intellectual ability. Problems with behavior appear less consistent, but the most frequently reported were somatic complaints, depression, and social problems. All of these deficits do improve with treatment, primarily in the form of adenotonsillectomy. However, the authors point out that there are only two studies that include a control group and use objective validated measures of both SDB and neurocognitive outcomes at baseline and in follow-up. In addition, the majority of treatment studies focus on primary school-aged children with little follow-up data extending beyond 1 year, highlighting the need for more rigorous prospective studies with longer follow-up.

With respect to the behavioral impact of sleep disturbances, a related review by Cassoff et $\mathrm{al}^{3}$ explores the evidence for the impact of sleep loss and other sleep disturbances on symptoms of ADHD. In addition to discussing the clinical implications of this relationship, the authors discuss hypothesized mechanisms involving changes in the prefrontal cortex, dopamine regulation, and the circadian system that may mediate the link between sleep disturbances and symptoms of inattention and hyperactivity. An important article in NSS further explores the relationship of short sleep duration and teacher ratings of inattention and cognition. ${ }^{4}$ This study demonstrates that shorter sleep duration is significantly associated with worse ratings in the inattention/ cognitive problems domain of the Conners' Teacher Rating Scale but not with the hyperactivity/impulsivity domain. ${ }^{4}$ Another article provided preliminary data that in pediatric
ADHD patients, better sleep hygiene before bed (eg, fewer caffeinated drinks, consistency of bedtime routine) predicts increased time in bed with improved sleep quality. In addition, observations that disrupted sleep is associated with weight and bedtime sleepiness, and that food consumption patterns are associated with morning sleepiness provide indirect evidence of a link between sleepiness, sleep quality, and eating behaviors in children with ADHD. ${ }^{5}$

Assessments of pediatric sleep have traditionally relied on either parental report of sleep history or objective measures such as polysomnography, considered the gold standard for diagnosis of a variety of sleep disorders. Several articles in NSS have used actigraphy as an alternative measure of sleep-wake patterns. ${ }^{4-6}$ Actigraphy uses a watch-like device that contains an accelerometer to measure physical activity. Estimates of sleep-wake states are then made based on algorithms using different thresholds of baseline activity to judge wakefulness. One recent study reported $86 \%$ sensitivity and $85 \%$ specificity of actigraphy in measuring sleep-wake states among infants when compared to polysomnography. ${ }^{7}$ When actigraphy was used as a gold standard to assess the accuracy of parental report of child sleep patterns among healthy children, subjective reports were judged to be acceptable for assessments of sleep start and end times but inadequate for total durations of sleep and nocturnal wakefulness. ${ }^{8}$ To assess whether this relationship holds true among children who are habitual snorers or suffer from insomnia, Dayyat et $\mathrm{al}^{6}$ compared sleep logs and actigraphy in children who were nonsnorers, habitual snorers, or had insomnia. All three groups showed a similar pattern of overestimated sleep duration of approximately 1 hour per night and an average error of 30 minutes in estimating sleep onset. It appears that actigraphy may provide more reliable objective data than parental report alone with respect to sleep-wake states and have a complementary role in assessing pediatric sleep habits at home.

While actigraphy provides a complementary objective measure of child sleep patterns, a subjective instrument allowing self-report among children aged 5-10 years is called the children's sleep comic. ${ }^{9}$ This approach was adapted from an unpublished German questionnaire named the "Freiburger Children's Sleep Comic" and utilizes cartoons to depict activities and scenarios related to sleep hygiene, sleep quality, and bedtime routines. This instrument was shown to have moderate correlations with other validated pediatric sleep questionnaires but has the advantage of being applicable to young children who do not yet read or write. Thus, this technique holds promise as an instrument that 
allows self-reported sleep symptoms even among very young children. Further prospective studies with longer follow-up are needed to establish its validity and potential utility in diagnosing pediatric sleep disorders. An example of such a prospective study was also published in NSS. This 5-year longitudinal study was based on self-report on the sleep-wake habits of teenagers aged $15-19$ years. ${ }^{10}$ Ikeda and Hayashi ${ }^{10}$ demonstrated that only $5 \%$ of students in this age-group consistently self-awakened (awakening without the need for an external stimulus) over the entire study period, while $56 \%$ consistently required forced awakening. In general, students who consistently self-awakened went to bed earlier, got up from bed earlier, slept for a longer time, and had less change in their sleep patterns over time. This longitudinal study with excellent long-term follow-up helped to confirm similar findings in previous cross-sectional studies.

Amid the growth of research in pediatric sleep, the first 100 articles published in NSS have covered a broad range of topics that are relevant to the diagnosis and management of pediatric sleep disorders. Whether these are review articles describing what is known about neurocognitive and behavior outcomes after treatment for SDB or reports on new diagnostic methods of characterizing pediatric sleep disorders, these articles illustrate the increasing depth and variety of research in this area. They also serve to highlight the need for further study in a field that presents unique challenges in the diagnosis and management of sleep disorders in different age ranges, and where new avenues of inquiry and opportunities for research abound.

\section{Disclosure}

The authors report no conflicts of interests in this work.

\section{References}

1. El Shakankiry HM. Sleep physiology and sleep disorders in childhood. Nat Sci Sleep. 2011;3:101-114.

2. Kohler MJ, Lushington K, Kennedy JD. Neurocognitive performance and behavior before and after treatment for sleep-disordered breathing in children. Nat Sci Sleep. 2010;2:159-185.

3. Cassoff J, Wiebe ST, Gruber R. Sleep patterns and the risk for ADHD: a review. Nat Sci Sleep. 2012;4:73-80.

4. Gruber R, Michaelsen S, Bergmame L, et al. Short sleep duration is associated with teacher-reported inattention and cognitive problems in healthy school-aged children. Nat Sci Sleep. 2012;4:33-40.

5. Spruyt K, Raubuck DL, Grogan K, Gozal D, Stein MA. Variable sleep schedules and outcomes in children with psychopathological problems: preliminary observations. Nat Sci Sleep. 2012;4:9-17.

6. Dayyat EA, Spruyt K, Molfese DL, Gozal D. Sleep estimates in children: parental versus actigraphic assessments. Nat Sci Sleep. 2011;3:115-123.

7. Galland BC, Kennedy GJ, Mitchell EA, Taylor BJ. Algorithms for using an activity-based accelerometer for identification of infant sleep-wake states during nap studies. Sleep Med. 2012;13(6):743-751.

8. Werner H, Molinari L, Guyer C, Jenni OG. Agreement rates between actigraphy, diary, and questionnaire for children's sleep patterns Arch Pediatr Adolesc Med. 2008;162(4):350-358.

9. Schwerdtle B, Kanis J, Kahl L, Kubler A, Schlarb AA. Children's Sleep Comic: development of a new diagnostic tool for children with sleep disorders. Nat Sci Sleep. 2012;4:97-102.

10. Ikeda H, Hayashi M. Longitudinal study of self-awakening and sleep/ wake habits in adolescents. Nat Sci Sleep. 2012;4:103-109.

Dove Medical Press encourages responsible, free and frank academic debate. The content of the Nature and Science of Sleep 'letters to the editor' section does not necessarily represent the views of Dove Medical Press, its officers, agents, employees, related entities or the Nature and Science of Sleep editors. While all reasonable steps have been taken to confirm the content of each letter, Dove Medical Press accepts no liability in respect of the content of any letter, nor is it responsible for the content and accuracy of any letter to the editor.

Nature and Science of Sleep

Dovepress

\section{Publish your work in this journal}

Nature and Science of Sleep is an international, peer-reviewed, open access journal covering all aspects of sleep science and sleep medicine, including the neurophysiology and functions of sleep, the genetics of sleep, sleep and society, biological rhythms, dreaming, sleep disorders and therapy, and strategies to optimize healthy sleep. The journal welcomes original research, clinical \& epidemiological studies, reviews \& evaluations, case reports and extended reports. The manuscript management system is completely online and includes a very quick and fair peerreview system, which is all easy to use. Visit http://www.dovepress.com/ testimonials.php to read real quotes from published authors. 